\title{
Amazon Deforestation and Climate Change
}

\author{
J. SHUKLA, C. NOBRE,* P. SELLERS
}

A coupled numerical model of the global atmosphere and biosphere has been used to assess the effects of Amazon deforestation on the regional and global climate. When the tropical forests in the model were replaced by degraded grass (pasture), there was a significant increase in surface temperature and a decrease in evapotranspiration and precipitation over Amazonia. In the simulation, the length of the dry season also increased; such an increase could make reestablishment of the tropical forests after massive deforestation particularly difficult.

The distribution of global vegetation was traditionally thought to be determined by local climate factors, especially precipitation and radiation. This view has been modified because controlled numerical experiments with complex models of the atmosphere showed that the presence or absence of vegetation can influence the regional climate (1 $\underline{1}-\underline{3})$. One implication of these results is that the current climate and vegetation may coexist in a dynamic equilibrium that could be altered by large perturbations in either of the two components. The high rate of deforestation in the Brazilian portion of Amazonia, from 25,000 to 50,000 km2 per year (4-ㄱ), might thus be expected to have an effect on the regional climate. If deforestation were to continue at this rate, most of the Amazonian tropical forests would disappear in 50 to 100 years.

Removal of the Amazonian forest would also have tremendous effects on species diversity and atmospheric chemistry (으). The Amazon basin is host to roughly half of the world's species, and the intensity and complexity of plant-animal interactions ( $\underline{9})$ and the rapid nutrient cycling in the soils $(\underline{10})$ make the region vulnerable to external disturbances. The Amazon is also an important natural sink for ozone and plays an important role in global tropospheric chemistry. The present study is mainly confined to the assessment of the effects of deforestation on the physical climate system.

Quantitatively estimating the effects that large changes in terrestrial ecosystems can have on temperature, circulation, and rainfall has been difficult because the equilibrium climate is determined by complex interactions among the dynamical processes in the atmosphere and thermodynamic processes at the earth-atmosphere interface. Realistic models of the biosphere that can be coupled with realistic models of the global atmosphere have only recently been 
developed $(\underline{11}, \underline{12})$. In this report, we describe the use of a coupled atmosphere-biosphere model $(\underline{13}, \underline{14})$ to investigate the consequences of the removal of Amazon forests on climate.

In the simulations, we assumed that the tropical forest cover (Fig. 1) is replaced by a degraded pasture. On the basis of observed changes in soil characteristics in deforested areas $(\underline{15} \underline{16})$, we also assumed that the soils in the deforested regions are disaggregated and that, as a result, values of the soil hydraulic conductivity and water storage capacity available for transpiration are greatly reduced in the upper part of the soil profile.

We have used a high-resolution global model of the atmospheric circulation ( $\underline{13})$ that describes and predicts atmospheric temperature, pressure, wind, and humidity at 18 different, unequally spaced levels between the surface and $30 \mathrm{~km}$. The horizontal resolution of the model at each level is about $1.8 \mathrm{deg}$. latitude by $2.8 \mathrm{deg}$. longitude. The largescale topography and sea-surface temperature (SST) are prescribed. The diurnal cycle is treated explicitly in the model, and both the convective and the large-scale saturation rainfall are calculated. For radiative calculations zonally symmetric clouds are prescribed rather than generated by the model. The global vegetation distribution at each land grid point is defined by 1 of 12 vegetation types, and each vegetation type is defined by a set of morphological, physical, and physiological parameters ( $\underline{17})$. There are three soil layers in the biosphere model: a thin evaporating upper layer, the root zone, and a recharge zone.

In the biosphere model $(\underline{12}, \underline{14})$, the wind speed, air temperature, incident radiative flux, and precipitation as calculated from the atmospheric model are used to predict the time rate of change of the model variables: canopy temperature; ground temperature; deep soil temperature; liquid water stored on canopy foliage and ground cover foliage; and the wetness of the surface thin layer, root zone, and recharge zone. Runoff, soil moisture, and sensible and latent heat fluxes are calculated as diagnostic outputs of the model.

We first integrated the coupled atmosphere-biosphere model for 1 year with the normal prescribed global climatological boundary conditions of vegetation distribution, in which the Amazonian region is covered with tropical forests (Fig. 1); we refer to this integration as the control case. We then repeated the integrations for 1 year in which all the previous global climatological boundary conditions remained the same except over Amazonia, where the tropical forests were replaced by a degraded pasture cover consisting mainly of grass; we refer to this integration as the deforestation case. In both the control and the deforestation cases, the global SST distributions remained inadvertently fixed for the whole integration period and corresponded to the climatological mean values for December.

The changes over Amazonia in the deforestation case, in effect, resulted in the alteration of a series of climatologically significant parameters. Relative to the tropical forest, the degraded pasture cover is calculated to have a higher albedo, lower surface roughness length, higher stomatal resistance, a shallower and sparser root system, and lower available storage capacity for soil moisture. The parameters for the control case were obtained from a literature survey and from an analysis of 2 years of in situ flux measurements $(\underline{18})$, whereas the parameters for the deforestation case were extracted from reports on fieldwork carried out in deforested areas $(\underline{16}$, $\underline{19}, \underline{20})$. 
The model integrations were started from an atmospheric state on 15 December, when the initial soil moisture in the region could be assumed to be at or near saturation in both cases, and integrations were carried out for 12.5 months. The results (Fig. 2) are in terms of 12-month averages (1 January to 31 December); the first 2 weeks of model integration are ignored. The annual cycle of temperature, precipitation, and evapotranspiration are shown as monthly averages.

Surface and soil temperatures are warmer by 1 deg. to 3deg.C in the deforestation than in the control cases. The relative warming of the deforested land surface and the overlying air is consistent with the reduction in evapotranspiration and the lower surface roughness length. This result is in agreement with results of an earlier simulation experiment (21) and some observations $(\underline{22}, \underline{23})$ for tropical forests.

The increase in surface temperature calculated in the deforestation case is reflected in differences in the surface energy budget for the two cases (Table 1). The absorbed solar radiation at the surface is reduced in the deforestation ease $(186 \mathrm{~W} / \mathrm{m} 2)$ relative to the control case $(204 \mathrm{~W} / \mathrm{m} 2)$ because of the higher albedo (21.6\%) for grassland compared to forest (12.5\%). The higher surface temperature in the deforestation case gives rise to more outgoing long-wave radiation from the surface compared to the control ease, so that the amount of net radiative energy available at the surface for partition into latent and sensible heat flux is considerably smaller in the deforestation ease. In addition, the reduced storage capacity for soil moisture in the deforestation case has the effect of reducing the time-averaged transpiration rate; also, in the deforestation case, less precipitation is intercepted and reevaporated as the surface roughness and the canopy-water holding capacity of the pasture are relatively small.

The reduction in calculated annual precipitation by $642 \mathrm{~mm}$ and in evapotranspiration by 496 $\mathrm{mm}$ (Table 2) suggests that changes in the atmospheric circulation may act to further reduce the convergence of moisture flux in the region, a result that could not have been anticipated without the use of a dynamical model of the atmosphere. Increased surface and soil temperatures produce some increase in the sensible heat flux (about 10 to $20 \mathrm{~W} / \mathrm{m} 2$, not shown); however, even the increased warming of the near surface air is not sufficient to increase the convergence of air (and moisture) into the region in the simulation.

Because evapotranspiration from the forest is one of the important sources of water vapor (24, 25) for precipitation in the Amazon, a reduction in evapotranspiration is expected to lead to a reduction in precipitation. However, because of the complexity of the atmosphere-biosphere system and the continuous interactions of dynamical and hydrological processes, a reduction in evaporation might be compensated for by an increase in moisture flux convergence. Our experiments indicate that such a compensation will not occur for the Amazon and that there is even a further decrease in convergence of the large-scale moisture flux. Whether this result is model-dependent can only be resolved by additional experiments and comparison with results from other models.

The differences in monthly mean surface temperature, precipitation, evapotranspiration, and evapotranspiration minus precipitation for the control and the deforestation cases are consistently of the same sign but of different magnitude for each of the individual months (Fig. 3 ). This 
consistency is partly a result of the large area for spatial averaging; similar time series for different, smaller subregions of the Amazon will show more variability from one season to the other. The value of evapotranspiration minus precipitation increased in the deforestation simulation. Runoff was also reduced in the deforestation case because the decrease in precipitation was more than the decrease in evapotranspiration.

A few significant changes in global circulation were also evident in the deforestation simulation, especially over North America; however, climatic fluctuations over the northern mid-latitudes are generally large in nature as well as in simulations even without any forced perturbations, and thus the anomalies may not be directly a result of the deforestation simulation. Moreover, the artificial constraint of time-invariant SST fields makes it difficult to draw any definitive conclusions about the global effects of Amazon deforestation from this study.

The most significant result of this study is the simulated reduction in precipitation over Amazonia, which is larger than the corresponding regional reduction in evapotranspiration, implying that the dynamical convergence of moisture flux also decreased as a result of deforestation. The spatial and temporal coherence of the decrease in precipitation implies that the deforested case is associated with a longer dry season. The lack of an extended dry season apparently sustains the current tropical forests, and therefore a lengthening of the dry season could have serious ecological implications (26-28). Among other effects, the frequency and intensity of forest fires could increase significantly $(\underline{29}, \underline{30})$ and the life cycles of pollination vectors could be perturbed.

These results suggest that a complete and rapid destruction of the Amazon tropical forest could be irreversible. Changes in the region's hydrological cycle and the disruption of complex plantanimal relations could be so profound that, once the tropical forests were destroyed, they might not be able to reestablish themselves.

13 October 1989; accepted 14 December 1989

Center for Ocean-Land-Atmosphere Interactions Department of Meteorology, University of Maryland College Park, MD 20742.

*Permanent affiliation: Instituto de Pesquisas Espaciais, 12201 Sao Jose dos Campos, SP, Brazil.

\section{REFERENCES AND NOTES}

1. J. G. Chamey, W. J. Quirk, S.-H. Chow, J. Kornfield, J. Atmos. Sci. 34, 1366 (1977).

2. J. Shukla and Y. Mintz, Science 215, 1498 (1982). 
3. Y. Mintz, in The Global Climate, J. T. Houghton, Ed. (Cambridge Univ. press, Cambridge, 1984), pp. 79-106.

4. P. M. Fearnside, in The Geophysiology of Amazonia, R. E. Dickinson, Ed. (Wiley, New York, 1987), pp. 37-61.

5. Instituto de Pesquisas Espaciais (INPE) Avaliacao da cobertura florestal na Amazonia Legal Utilizando Sensoriamento Remoto Orbital (INPE, Sao Jose dos Campos, SP, Brazil, 1989).

6. N. Meyers, Acta Amazonica 12, 745 (1982).

7. D. J. Mahar, Government Policies and Deforestation in Brazil's Amazon Region (World Bank, Washington, DC, 1989).

8. R. A. Houghton et al., Nature 316, 617 (1985).

9. S. A. Mori and G. T. Prance, in The Geophysiology of Amazonia, R. E. Dicknson, Ed. (Wiley, New York, 1987), pp. 69-90.

10. A. C. C. P. Dias and S. Nortcliff, Trop. Agric. 62, 207 (1985).

11. R. E. Dicknson, A. Henderson-Sellers, P. J. Kennedy, M. F. Wilson, Biosphere-Atmosphere Transfer Scheme (BATS) for the NCAR Community Climate Model (Tech. Note TN-275+STR, National Center for Atmospheric Research, Boulder, CO, 1986).

12. P. Sellers, Y. Mintz, Y. C. Sud, A. Dalchcr, J. Atmos, Sci. 43, 505 (1986).

13. J. L. Kinter, J. Shukla, L. Marx, E. K. Schneider, ibid. 45, 2486 (1988).

14. N. Sato et al., ibid. 46, 2757 (1989).

15. H. Shubart, W. J. Junk, M. Petrere, Jr., Ciencia Cult. (Sao Paulo) 28507 (1976).

16. C. Uhl et., al., J.. Ecol. 76, 663 (1988).

17. J. L. Dorman and P.J. Sellers, J. Appl. Meteorol. 28, 833 (1989).

18. P. J Sellers, W. J Shuttleworth, J. L. Dorman, A. Dalcher, J. M. Roberts, ibid., p. 727.

19. M. M. Ludlow, M. J. Fisher, J. R. Watson, Aust. J. Plant Physiol. 12, 131 (1985).

20 G. T. Prance and T. E. Lovejoy, Amazonia (Pergamon, New York, 1984).

21. R. E. Dickinson and A. Henderson-Sellers, Q.J. R. Meteorol Soc 114, 439 (1988). 
22. B. S. Ghuman and R. Lal, in The Geophysiology of Amazonia, R. E. Dickinson, Ed. (Wiley, New York, 1987), pp. 225-244.

23. T. L. Lawson, R. Lal, K. Oduro-Afriyie, in Tropical Agriculture Hydrology, R. Lal and E. W. Russel, Eds. (Wiley, New York, 1981), pp. 141-151.

24. E. Salati and P. B. Vose, Science 225, 129 (1984).

25. W.J Shuttleworth et al., Q.J.R. Meteorol Soc. 110, 1143 (1984).

26. H. N. Le Houerou and G. F. Popov, An Eco-Climate Classification of Intertropical Africa (Food and Agriculture Organization, Rome, 1978).

27. W. Lauer, in Ecosystems of the World Tropical Rain Forest Ecosystems, M. Leith and M.J.A. Werger, Eds. (Elsevier, New York, 1989), vol. 14B, pp. 7-54.

28. A. Hamilton, ibid., vol. 14B, pp. 155-182.

29. H. O'R. Sternberg Gogr. Ann. Ser. A 69, 201 (1987).

30. R.L. Sanford Jr. J. Saldarraga, K.E. Clark, C. Uhl, R. Herrera, Science 227, 53 (1985).

31. We thank J.Kinter, L. Marx, M. Fennessy, and E. Schneider for help in conducting this simulation experiment, P. Dirmeyer for help in the processing and diagnosis of model outputs and A. D. Nobre for providing information about the Amazonian ecosystem. We also thank S. Busching for help in the preperation of the manuscript and L. Rumburg for drafting the final figures. This research was supported by National Science Foundation grant ATM-87-13567 and National Aeronautics and Space Administration grants NAGW-1269 and NAGW-557. 